\title{
PROBLEMS OF CONSTRUCTING WIND-DIESEL POWER PLANTS IN HARSH CLIMATIC CONDITIONS
}

\author{
Dr Victor Vasilievich Elistratov* \\ Institute of Civil Engineering,Saint-Petersburg State Polytechnical University, Saint-Petersburg, Russia \\ Dr Miloš Knežević \\ Faculty of Civil Engeneering, University of Podgorica, Podgorica, Montenegro \\ Roman Denisov \\ Institute of Civil Engineering,Saint-Petersburg State Polytechnical University, Saint-Petersburg, Russia \\ Michael Konishchev \\ Institute of Civil Engineering,Saint-Petersburg State Polytechnical University, Saint-Petersburg, Russia
}

The energy supply of buildings on the basis of renewable energy is a topical problem of the modern construction science. Wind power is the most modern and perspective direction in renewable energy both in Russia and Serbia. In the northern regions of Russia, the increase of reliability and efficiency of power supply is suggested to be solved by constructing wind-diesel power plants and optimizing the composition of equipment, parameters and modes of operation. In the article, the major problems faced during the process designing of wind-diesel power plants in harsh climatic conditions are considered. The complexity is associated with building and using wind turbines. There are the problems of transport logistics, of the construction on the permafrost, the installation and adaptation of equipment to harsh climatic conditions. In the article, the major issues increasing the reliability of operation are described. A number of considered issues are analyzed and solutions are proposed regarding the design documentation to construction of WDPP in the Yamal-Nenets Autonomous District. The recommendations for choosing the basic equipment are described. The parameters of WDPP with high penetration are optimized using the software package HOMER 2.81.

Key words: Energy-efficient technologies in building, Wind-diesel power plant, Wind turbine, Building, Harsh climatic conditions

\section{INTRODUCTION}

By the present moment, the development of renewable energy sources (RES) in Russia has been supported by the legal framework on the one hand and by the economic incentives for the development of renewable energy on the wholesale market in the centralized generation on the other hand. It has also been reflected in the RF Government Decree № 449 of 28.05.2013 «On the mechanism of promoting the usage of renewable energy in the wholesale market of electrical energy and power».

At the same time $65 \%$ of Russian territory is located in the autonomous areas of electricity supply including those in the northern regions. It means that the development of renewable energy is an urgent task in the regions of decentral- ized energy supply. In the northern regions of the country, the basis of power production is diesel power plants (more than 3 million kW). Most of them outlived their useful life long time ago. They have a very high fuel consumption level for electricity production and consequently they have a high (up to $1 € / \mathrm{kWh}$ ) cost of energy production. As a rule, the development of renewable energy and economic efficiency in the autonomous areas can be achieved by saving long-range fuel. As it is shown in Figure 1, the regions of decentralized energy supply are located on the territory with high wind potential (with an average wind speed of $5 \mathrm{~m} / \mathrm{s}$ and specific capacitance of more than $400 \mathrm{~W} / \mathrm{m} 2$ [04]). The world experience of the United States (Alaska), Canada, Finland, Norway and Sweden and other countries with similar climatic conditions proves that the 
most efficient way is to create wind-diesel power plants (WDPP) in the northern regions.

The implementation of WDPP provides the following effects [07]:

- enhancing of energy security of remote regions of Russia by increasing self-sufficiency in local fuel and energy resources;

- $15-20 \%$ reduction in energy loss due to the transmission and distribution of energy and therefore improvement of reliability and reduction of costs of energy for the consumer;
- reducing the amount of long-range fuel;

- greening regional power by reducing harmful emissions into the environment and reducing the volume of importation of diesel fuel barrels to the North.

The construction and the operation of wind-diesel power systems in northern conditions require solving a number of problems: economic efficiency, providing quality power supply, delivering and installing equipment, constructing on permafrost, etc. Let us briefly analyze these problems and their solutions.

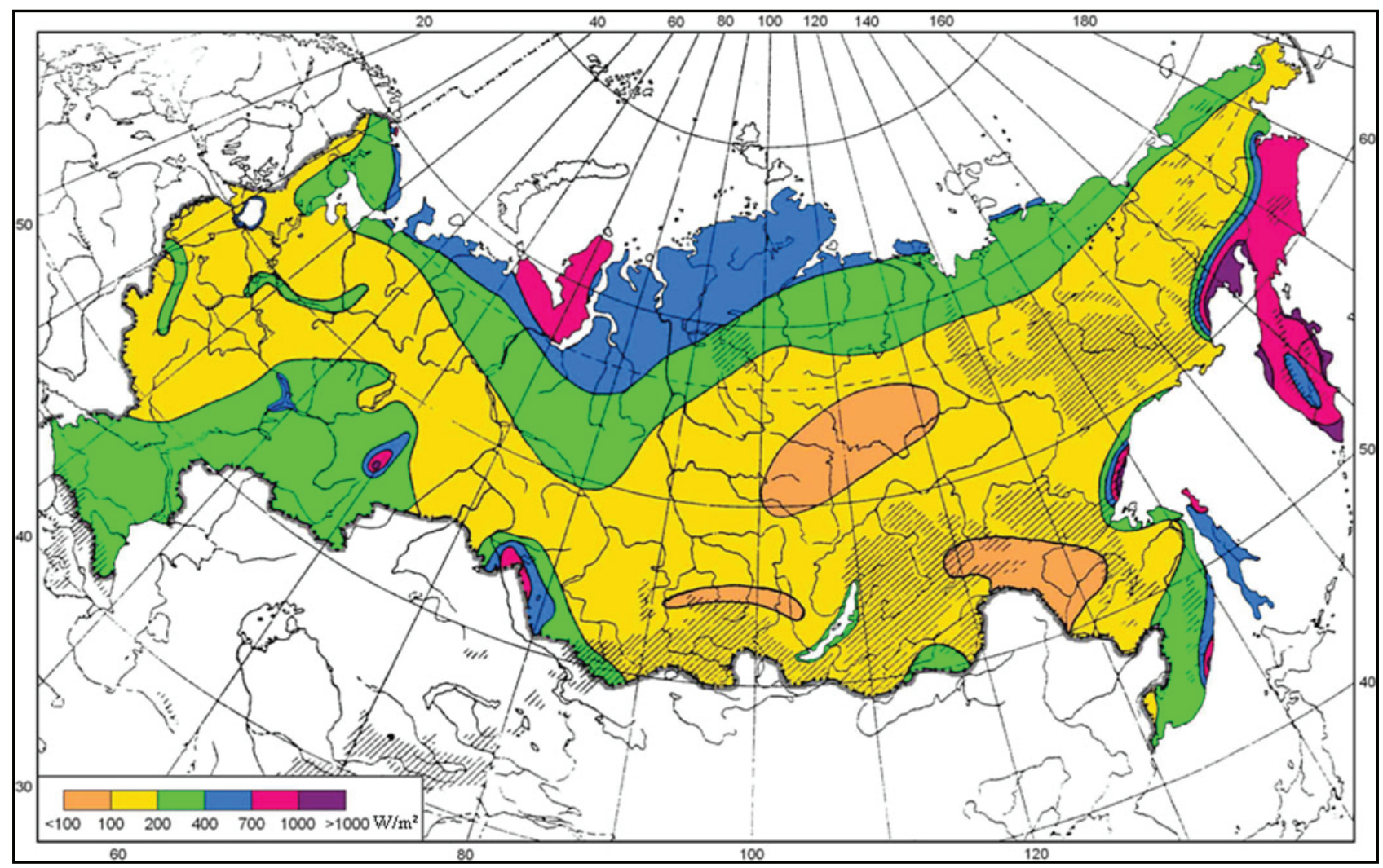

Figure 1: Value of specific capacitance of wind flow in Russia at $100 \mathrm{~m}$

\section{THE PROBLEM OF INCREASING THE EFFECTIVENESS OF NORTHERN WDPP}

The increase of the reliability and efficiency of power supply is suggested to be solved by increasing the penetration of expensive long-range fuel through optimizing the composition of equipment, parameters and modes of operation. The classification by the penetration class of WDPP is shown in Table $1[03,15]$.

The functional schemes of WDPP can be divided into two management options:

1) Diesel driven generators (DDG) work in the grid constantly and monitor the load. Wind turbines (WT) work in parallel with DDG and reduce the load on DDG to a minimum level (to save the fuel);

2) DDG may be switched off during periods of heavy production by wind turbines which can operate in the coating of the load without DDG.

The first option does not impose any specific requirements for the management system and does not require any use of special means of regulation. As it can be seen from the table, systems with low or medium penetration can be operated in this management option of WDPP. 
Table 1: Penetration class of WDPP

\begin{tabular}{|c|c|c|c|}
\hline \multirow{2}{*}{$\begin{array}{l}\text { Penetration } \\
\text { class }\end{array}$} & \multirow{2}{*}{ Operating Characteristics } & Penetration, \% & Penetration, \% \\
\hline & & Peak Instantaneous & Annual Average \\
\hline \multirow[b]{2}{*}{ Low } & Diesel(s) run full-time & \multirow[b]{2}{*}{$<50$} & \multirow[b]{2}{*}{$<20$} \\
\hline & No supervisory control system & & \\
\hline \multirow{2}{*}{ Medium } & Diesel(s) run full-time & \multirow{2}{*}{$50-100$} & \multirow{2}{*}{$20-50$} \\
\hline & Requires relatively simple control system & & \\
\hline \multirow{2}{*}{ High } & Diesel(s) may be shut down during high wind & \multirow{2}{*}{$100-400$} & \multirow{2}{*}{$50-150$} \\
\hline & Requires sophisticated control system & & \\
\hline
\end{tabular}

The system with medium penetration has a more complex control system that increases its cost. Additional costs are mainly compensated by the reduction of diesel consumption and, thus, by the cost of the fuel component.

As a rule, WDPP with a high penetration is the second option. When operating such WDPP, DDG are switched off during the periods when energy generated at WPP is enough to cover the load that provides maximum fuel economy. However, this scheme requires additional equipment to control the frequency and voltage in the case of autonomous operation of WPP (subsidiary diesel generators, uninterruptible power supply

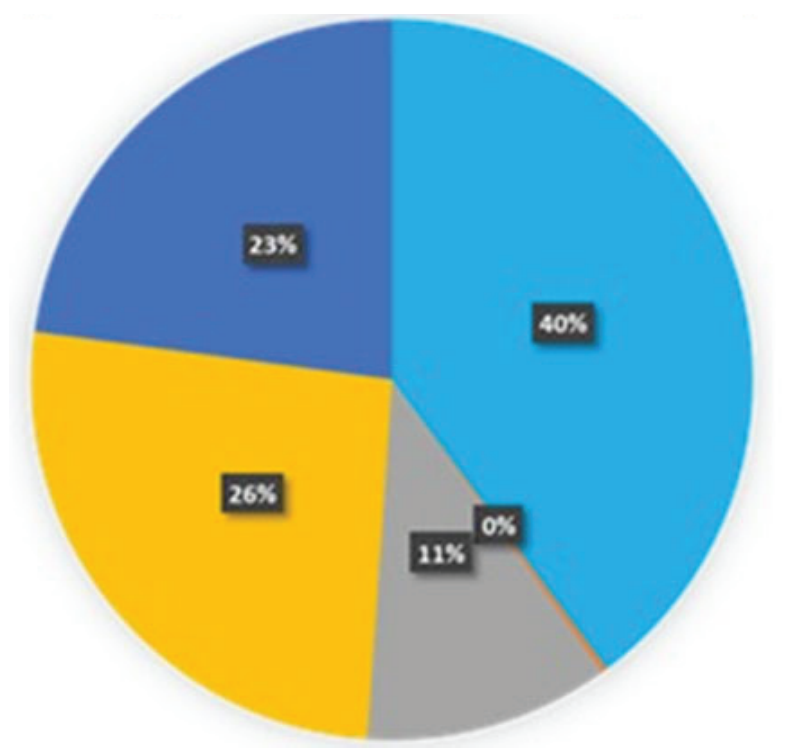

WDPP permanent equipment

Object of energy utilitities

Cost of transportation

Installation and construction works

Other costs (technical inspection, VAT, unanticipated needs)

Figure 2: The structure of the investment in the project of WDPP

The diagram shows that the construction, installation and transport costs in the total investment are more than $35 \%$. Therefore, it is extremely important to optimize and minimize these components.

\section{THE PROBLEM OF TRANSPORT LOGISTICS OF WIND TURBINE AND ITS COMPONENTS}

The lack of well-developed road infrastructure is the most important issue in the construction of wind turbines in harsh climatic conditions, which requires a more careful study of logistics. The 
transportation of long blades of wind turbines requires a special transport, however, this transport has significant turning radius (Figure 3 ). Under these conditions, the delivery of marker equipment is a challenge. The presence of the curved sections (for example, in the mountains) with a large number of slopes and relatively small turning radius requires the usage of special equipment cranes and trailers on which the equipment is transported to the place of its installation [04]. In the Far North, the problems of transportation are associated with high dispersion of territorial settlements and poor transport links. The transport period for many northern regions is only 23 months and is carried out on temporary, unequipped routes. One of possible solutions to this situation can be a helicopter delivery and the installation of wind turbines.

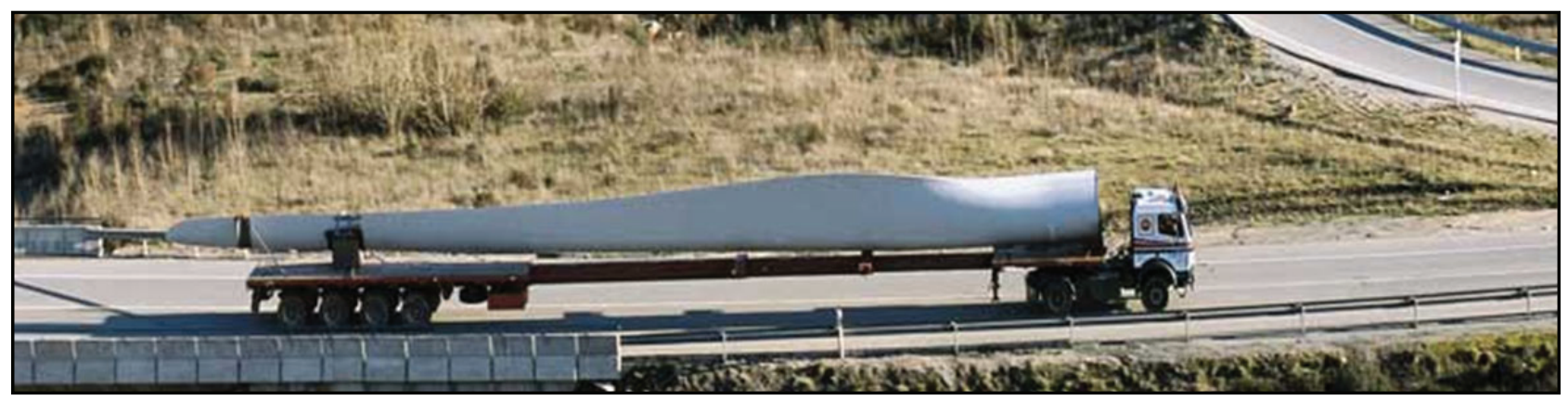

Figure 3: The transportation of blades

THE PROBLEM OF THE CONSTRUCTION OF THE WIND TURBINES FOUNDATION ON THE PERMAFROST

As a rule, the construction in Northern regions is associated with the construction on the permafrost. The permafrost is regarded as soil existing continuously in the frozen state for several years. Currently, permafrost in Russia is about a quarter of land.

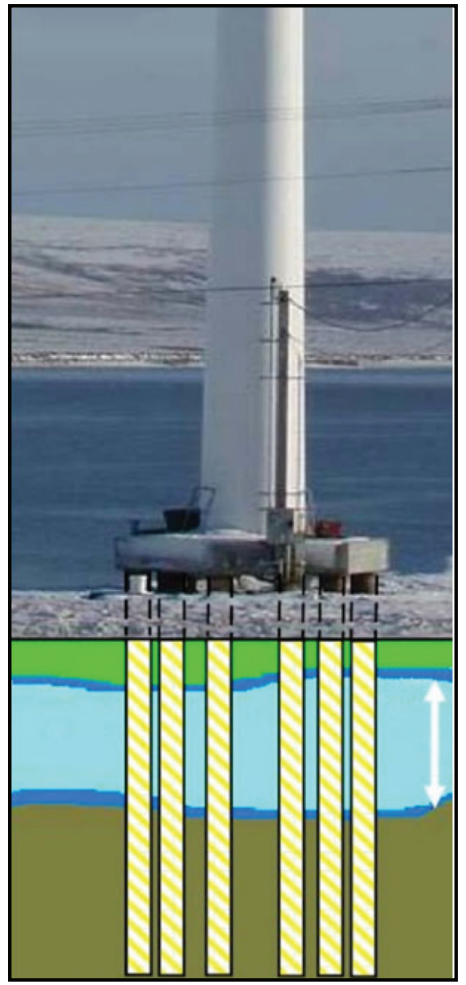

Figure 4: The pile foundation with a high grillage
When building the foundation of any construction project based on permafrost conditions, including wind turbines, have to be created so that the permafrost remains in a consistent state are necessary to create. As a rule, the foundations of these objects have a high grillage and a pile foundation allowing the creation of a ventilated foundation (Figure 4). At the moment three types of piles are used in the construction of wind turbines such as drilled piles, drilling down (using lime-sand mortar) piles and in-situ piles (the frame filled with reinforced concrete in situ) [6]. The thermo-syphon cooling methods of pile foundation of wind turbines are also applied to preserve the integrity of permafrost so that inservice permafrost base is not thawed.

\section{THE INSTALLATION PROBLEM OF WIND TURBINE IN HARSH CLIMATIC CONDITIONS}

WPP is a unique construction which in contrast with chimneys has a massive system "rotor - nacelle" located at a considerable height above the ground which creates considerable external forces and requires unique cranes with a large arm for mounting elements of a tower, a wind wheel, a nacelle etc. In regions with poorly developed transport infrastructure where it is very difficult to deliver a crane jack-up, wind turbines are used which, however, have small nomenclature especially for northern conditions [01, 80, 09] (Fig. 5). In remote places, the assembly by the usage of a helicopter is possible. 


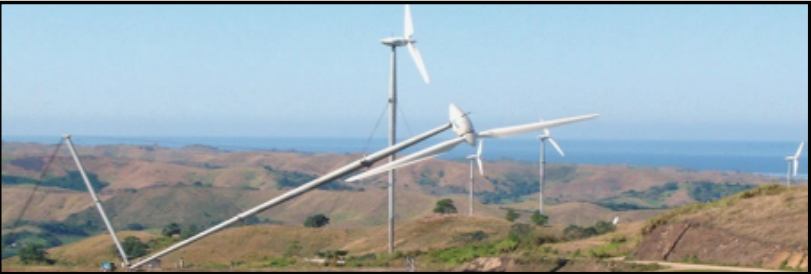

Figure 5: The installation of jack-up wind turbine

\section{THE PROBLEM OF ADAPTING EQUIPMENT TO HARSH CLIMATIC CONDITIONS}

In areas where the temperature drops below $30{ }^{\circ} \mathrm{C}$ rime is often formed, thus, we should fight with glaciations of the equipment which can lead to malfunction of the equipment and the disruption in power supply to consumers. In connection with this problem, there are various deteriorating situations depending on the type of equipment and facilities to deal with them.

a) For blades; glaciations cause downtime. If the wind turbine is in operation, the increase in mass of the blade due to an uneven buildup of snow can cause its destruction and can endanger the safety of the object. The methods of deicing include:

- heating systems blades;

- paint blades black and/or a special hydrophobic polymeric coating which has improved adhesion to sticking [16];

- strengthening of special tapes in hazardous to stick;

- ultrasonic treatment methods of blades which are now under development and experimen- tation.

According to the research, heating systems require a large power consumption for own needs $(10 \%)$ and increase the risk of fire.

b) Main power equipment is located in the nacelle of wind turbines, so it is advisable to ensure the safe operation of heating the most critical components (gearbox, generator, control boxes, bearings, blades turning control system, etc.).

c) For towers of wind turbines cold-resistant low-alloy steel types are used in operation at low temperatures [10]. Nickel of all the alloying elements lowers in the most degree cold brittleness of steel. Nickel and iron are completely soluble in each other; they have similar crystal structure of lattices. The dissemination can get towers from low-carbon steels as weldability improves with reduced carbon content. Stairs leading to the gondola must be necessarily inside the tower.

d) Stationary equipment (DDG, additional DDG, batteries, control panels) is advisable to use a block-container layout of equipment for the adaptation of northern conditions. In a blockcontainer, the equipment is located in a wellventilated, heated, insulated and sealed place. In the factory, settings are made "flat-to-flat». In Russia such containers are produced by several plants including plants «Zvezda», LLC «SpetsElectroSistemy» [17]. One example of a container is shown in Figure 6.

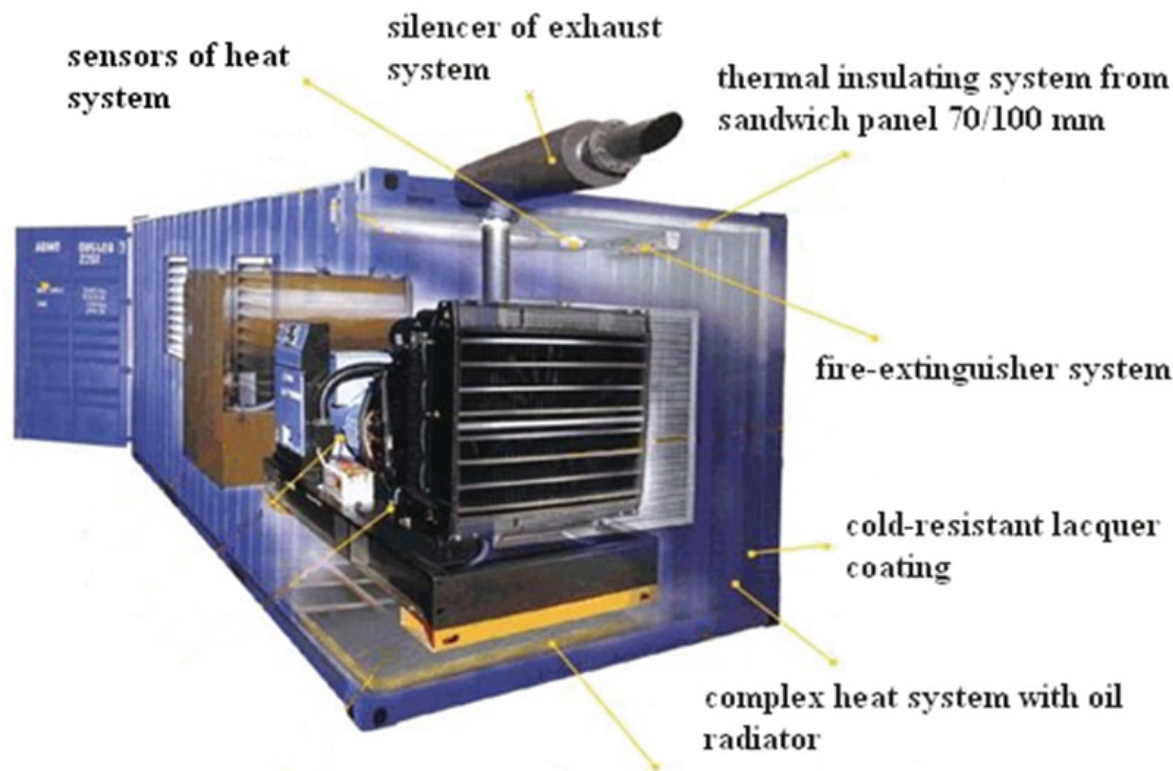

floor heat insulation

Figure 6: Scheme of block-container «Sever» 
Changes of rate speed of the wind wheel and the power of wind turbine occur in the operation of wind turbine at variable-speed wind. Therefore sudden changes in the quality of issued electricity to consumer can occur which should be considered by a control system and to be allowed to fluctuate within acceptable limits [12]. When designing WDPP, it is important to pay attention to the equipment belonging to the energy complex. Considering the fact that the northern regions are the regions of independent power supply it is recommended to choose gearless wind turbines with synchronous generators with permanent magnets (PMSG) and a full-scale power converter (Figure 7) [09]. The lack of gear significantly improves the reliability of the system to it allows wind wheel to work with variable speed. The work at low speeds ensures optimum power generation at low wind speeds. The application of full-scale power converter creates a galvanic isolation frequency in the circuit and increases the manageability of power quality at the end user by controlling the semiconductor elements.

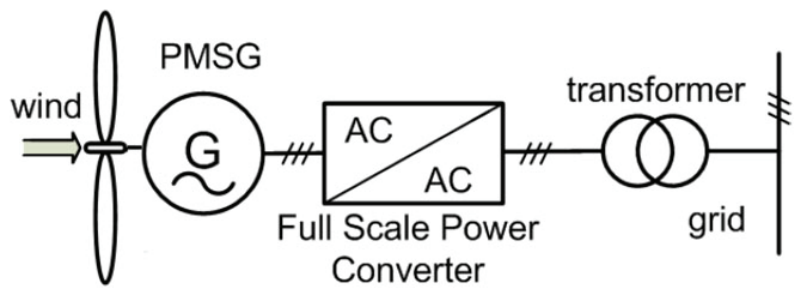

Figure 7: Scheme of wind turbine with PMSG

A number of considered issues has been analyzed and solutions are proposed in the design documentation construction WDPP in the Yamal-Nenets Autonomous District [02, 05]. The object is located at $67^{\circ}$ north latitude. Creation of WDPP is suggested to be due to the extension of two wind turbines to the existing DDG (two DDG $256 \mathrm{~kW}$ ) and the use of additional equipment for special northern execution. There are selected wind turbines Northwind 100 Arctic $(100 \mathrm{~kW})$ from Northern Power Systems, USA. These units feature high reliability thanks to the maximum simplification of the structure and reducing the number of moving parts by eliminating the usage of gear using low-speed synchronous generator with permanent magnets. Distinctive features of the model NPS 100 Arctic are able to function in a temperature range from $-40^{\circ} \mathrm{C}$ to $+50^{\circ} \mathrm{C}$ and high humidity and the presence of special passive protection against icing of blades in the form of a hydrophobic polymer coating black. Nacelle of wind turbine is heated to ensure the safety and comfort of personnel during periods of repair or maintenance and access to nacelle is possible by stairs located inside a tower. The tower of wind turbine consists of three parts so it is the complexity of a design flaw in the assembly for which one need to use a crane with a large arm.

Calculations were performed using the software package «HOMER 2.81» for optimization of the equipment and modes of WDPP in v. Yar-Sale. Operating window with example calculations is shown in Figure 8. Software package allows to simulate the composition of equipment, considering the wind speed, the oscillations of the load curve, determining the fuel consumption for different schemes, as well as the cost of investment for the options under consideration.

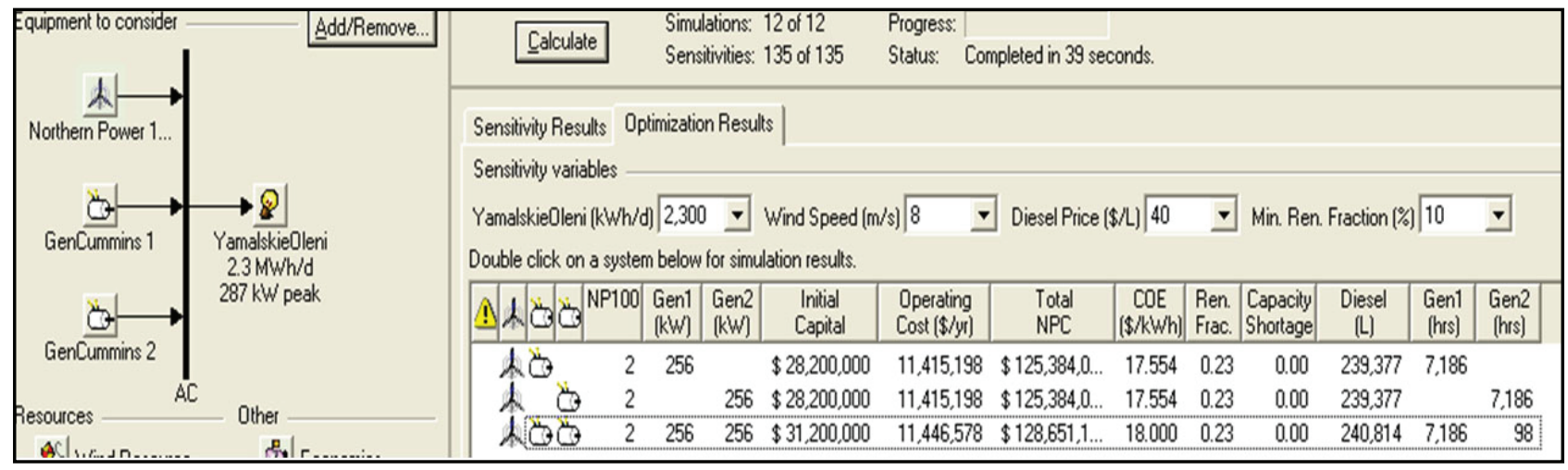

Figure 8: Operating window of HOMER

Calculations were performed for three options schemes of the equipment:

1) With low penetration (DDG $+2 W T)$;

2) With medium penetration (DDG + 2 WT + add DDG);
3) With high penetration (DDG + 2 WT + add DDG + batteries).

To select and justify the power of additional equipment and energy storage systems authors 
propose efficiency functional $F$ that generally represents the proportion of differential substitution $\mathrm{K}_{\mathrm{z}}$ power $\mathrm{P}$ (battery capacity $\mathrm{C}$ ):

$F=\frac{d K_{Z}}{d P(d C)}$

Additional DDG is selected in the power range from 6.5 to $105 \mathrm{~kW}$ and a block from 12 to 120 capacity batteries $200 \mathrm{~A} \cdot \mathrm{h}$. An additional diesel generator capacity of $64 \mathrm{~kW}$ and a block of 24 batteries are selected from the Evaluation of the function of the efficiency and feasibility study. The scheme of the selected parameters and equipment WDPP is shown in Figure 9.

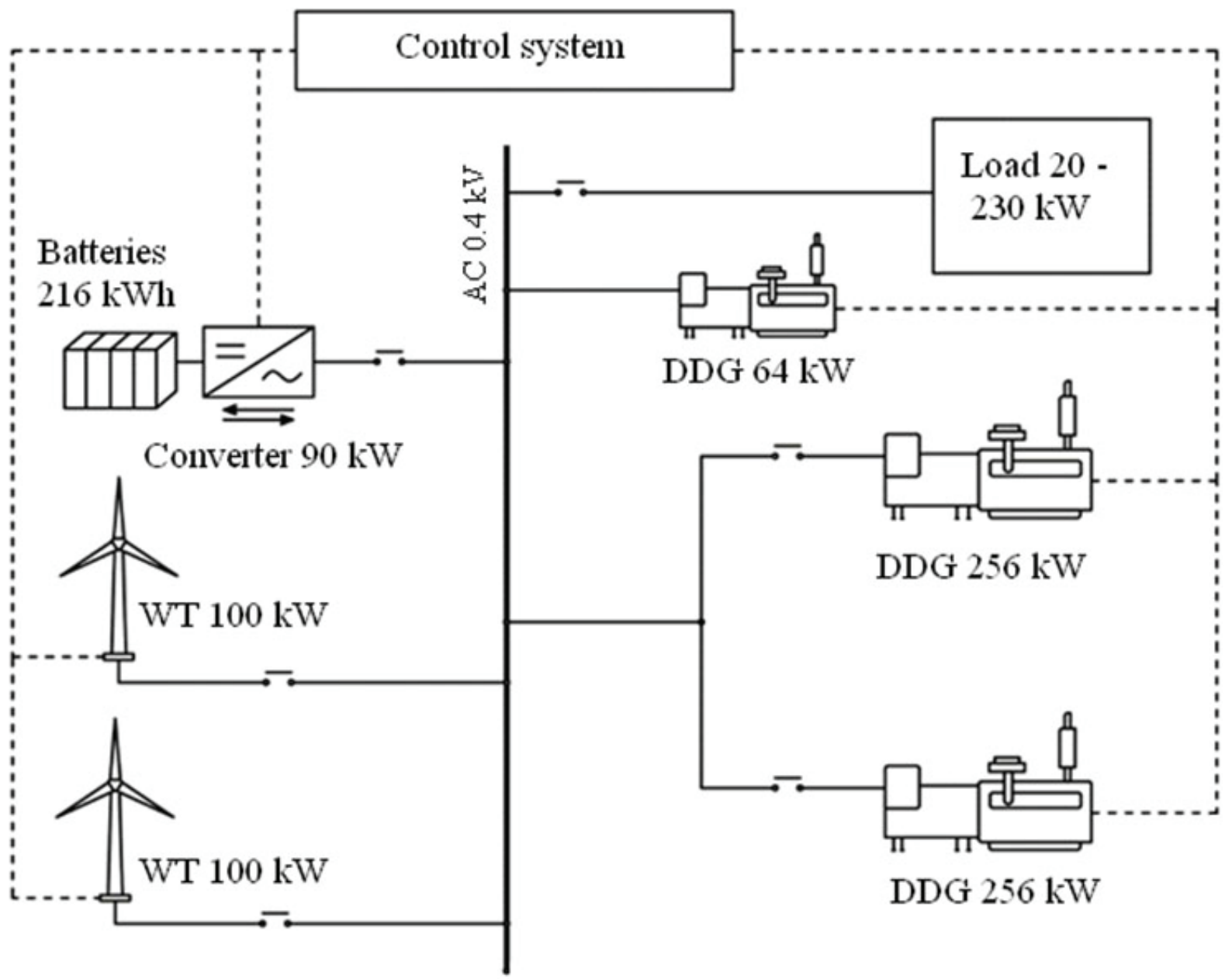

Figure 9: Scheme of WDPP with high penetration

Table 2. Techno-economic comparison of options schemes

\begin{tabular}{|c|c|c|c|c|}
\hline \multirow{2}{*}{ Scheme } & \multirow{2}{*}{ DDG } & $\begin{array}{c}\text { WDPP with level } \\
\text { penetration }\end{array}$ & $\begin{array}{c}\text { WDPP with level } \\
\text { penetration }\end{array}$ & $\begin{array}{c}\text { WDPP with level } \\
\text { penetration }\end{array}$ \\
\cline { 3 - 5 } & 0 & low & medium & high \\
\hline Penetration, \% & 23 & 44 & 53 \\
\hline Fuel consumption, I/year & 300,301 & $\begin{array}{c}240,814 \\
(-59,186)\end{array}$ & $\begin{array}{c}164,570 \\
(-135,731)\end{array}$ & $\begin{array}{c}136,881 \\
(-163,420)\end{array}$ \\
\hline $\begin{array}{c}\text { Effect of introduction WDPP, K } \\
\text { euro/year }\end{array}$ & 0 & 60 & 90 & 108 \\
\hline
\end{tabular}

Share of displace diesel fuel cost and estimated effects from the introduction of each of the three options are calculated in the software package
Homer. The main conclusions are summarized in Table 2. 


\section{CONCLUSION}

1) The urgency of building of WDPP in areas of independent power supply in harsh climatic conditions is substantiated, existing problems of construction WDPP are described and solutions to these problems are presented.

2) As the example of solutions to the problems listed above, the project of WDPP in Yar-Sale is considered.

3) As a result of the feasibility study, the composition and parameters of the equipment of WDPP are matched to ensure high penetration of diesel fuel.

4) As a result of the simulation the penetration of WDPP using automated and intelligent system power storage appeared to be $53 \%$. The fuel saving of WDPP was about 160,000 tons/year and the discounted payback period was 6.3 years.

\section{REFERENCES}

1) Cvetkovska M., Todorov, K., Lazarov, L. Axial restraint effects on fire resistance of statically indeterminate RC beams, Journal of Structural Fire Engineering № 4(1), pp 47-58

2) Denisov R., Elistratov V. (2013): The use of WDPP with high penetration in distribution generation, Abstract First Intenational Forum "Renewable energy: towards raising energy and economic efficiencies": Moscow, RAS, p 394

3) Drouilhet, Steve, Shirazi, Mari (2002) Recent Operating Experience with the Wales, Alaska, High Penetration Wind-Diesel System: Anchorage

4) Elistratov V. (2013) Renewable energy: Saint-Petersburg, Nauka

5) Elistratov V., Konischev M. (2013): Wind turbine operation in distributed and isolated generation, Abstract First Intenational Forum "Renewable energy: towards raising energy and economic efficiencies": Moscow, RAS, pp 394-395

6) Elistratov V., Panfilov A. (2011) Design and operation of the renewable energy sources installations: Saint-Petersburg, Polytechnical University

7) Frye Jack A. (2006) Performance Objective Design of a Wind-Diesel Hybrid Energy System for Scott Base, Antarctica: Master's Thesis
8) Fric, N., Gligić B., Dobrić J., Marcović Z. (2012) Wind towers - design of friction connections for assembling sections of tubular steel towers, Journal of Applied Engineering Science, Vol. 10, No 1, pp 49 - 52

9) Iov F., Ciobotaru M., Blaabjerg F. (2007) Power Electronics Control of Wind Energy in Distributed Power Systems: Aalborg University

10) IEC $61400-21$, Wind turbine generator systems. Part 21: Measurement and assessment of power quality characteristics of grid connected wind turbines

11) Kansara Bindu U., Parekh B.R. (2013) Dispatch, Control Strategies and Emissions for Isolated Wind-Diesel Hybrid Power System, International Journal of Innovative Technology and Exploring Engineering, Vol.2, No 6, pp 152 - 156

12) Kanthwal A., Ganesh A. (2012): Hybrid WindDiesel Generation System, International Journal of Applied Engineering Research, Vol. 7, No 11, pp 1342-1347

13) Lazarevska, M., Trombeva-Gavriloska, A., Knezevic, M., Samardzioska, T., Cvetkovska, M., (2012): Neural network prognostic model for RC beams strengthened with CFRP strips, Journal of Applied Engineering Science, № 1 (10), pp. 27-30.

14) Milovančević M., Anđelović B. (2010) Modern techniques of wind turbine condition monitoring, Journal of Applied Engineering Science, №8, pp 33 - 38

15) Muhando, Billy, Keith, Katherine, Lundsage, Per (2012) Best Practices in Implementation of WIND-DIESEL SYSTEMS: AlaskaAlaska Center for Energy and Power

16) Zubarev V., Minin V., Stepanov I. (1989) Usage of wind energy in North: state, efficiency conditions and prospects: Saint-Petersburg, Nauka

17) http://www.spelsy.ru/, retrieved on December $6^{\text {th }}, 2013$

Paper sent to revision: 07.02.2014.

Paper ready for publication: 15.03.2014. 